\title{
The Essence of Symbols on Igbo Modern Thrones
}

\author{
Ogbu Chinyere Happiness
}

\author{
Department of Industrial Design \\ School of Environmental Sciences \\ Modibbo Adama University of Technology, Yola
}

\section{Doi:10.5901/mjss.2013.v4n6p457}

\section{Abstract}

This paper takes up the issue of the essence of symbols on Igbo modern thrones. Our attention therefore centre on the symbolic motifs on Igbo modern thrones in Anambra State of Nigeria. It pays a particular attention on the modern thrones in Onitsha, Awka and Nri which statistics show have modern throne with hybrid symbolism. The study begins with the classification of motifs on the artifacts of our study. It went further to interpret the individual symbols as well as providing the iconographic and functional analysis of the interpreted motifs in the peoples context using field information to cross-check the available literature. Photographs of the thrones and their associated symbolic motifs were provided. The study aimed at unavailing the Igbo ideology of symbolism in the presence of modernization in their use and choice of symbols. It also showed a shift and elaboration of symbolism as a result of change in ideology, occupation and general world view. We high-lightened the existence of incorporation of new found motifs, functions and meanings and the individual reaction of them in view of leadership and governance. This exercise, noted that all forms of symbolic motifs around the thrones underscore historical facts. While some reflect the modern trend in lgbo land, others maintain the strength of tradition. Christian motifs and some emblems on the thrones reveal the impact of Christianity in lgbo culture, others serve as a reflection of modern concept of power with its political shift and values. The compressed and ideological statements of the symbolism gave the thrones and their occupier greater power than are lodged on a mere sitting material and an ordinary person.

\section{Introduction}

The Igbo people consolidate the foundations laid by their ancestors by exploiting the cultural heritage which they thereafter improve upon. Ogbu (2005) wrote that "it is unfortunate that the old people of the society are dying and with them the heritage and cosmology which were the pride and binding force of the society".

This dynamic and energetic ethnicity as contained in Ogbalu (n.d) like any other in Africa and Nigeria in particular is richly endowed with material culture. These material culture noted Nsofo (1977) Onwugeogwu (1972), Eyo (1977) Oyelola (1976) and Cole of Aniakar (1984) were incorporated into their artifacts which serve as the encapsulation of Igbo ideology of life which culminated in their world view.

History has shown in Fag and Plast (1964) that the greatest asset on man by nature has been the availability of immense and vast expance of vegetation made up of various types of trees, animals etc. these assets man has earnestly harnessed and artistically transformed into human character in form, ideology and tale context for the onward movement of life, one of which is the optimal manipulation of societal politics.

In terms of creativity per-excellence, the Igbos are at the forefront (Shaw 1970 and 1977). Here, their skillful manipulation and expertise control of art media and materials are unprecedented. Good examples are recorded in Nsofor (1977) on the metal works of the Awka Smith and their Igbo - Ukwu counterparts in the Igbo areas.

Onwuejeogwu (1981) and Cole and Aniakor (1984) equivocally affirmed that the characteristics, quality and quantity of the artifacts of the people are unparallel. The peoples range of artifacts visually reveal a vast number of symbolic representation of motifs especially on their items of royalty such as the modern thrones (Ogbu, 2005).

It is note worthy that Shaw (1977) marveled when he unveiled a vast artistic tradition of the Igbo people in IgboUkwu. The artifacts noted Cole and Aniakor (1984) revealed several motifs which occurred on almost every art object excavated which is associated with this historic art centre, which were either related to ritual, leadership, masking, architectural embellishment or items of authority.

The result of these symbolic forms are seen in numerous modern artifacts of Igbos especially on their modern thrones as contained in Ogbu (2005) and whose range of symbolism this paper seek to address. 
An oral interview rendered by a custodian of oral tradition and history (Matthew Okafor, 2005) provides a good take off into the theme of this paper. He narrated that "thrones are instruments of power which Igbo traditional leaders use to carry out their political activities such as presiding over political matters. They are also used to perform religious functions such as the breaking of kolanuts and offering of sacrifices and prayers to the ancestors. Thrones are also essential symbols used in the maintenance of social order and festivals involving ceremonies such as the coronations and Ofala".

Further to this is Cole and Frasser (1972) who noted that "the instrument of power are many and diverse. Important men everywhere reinforce their position, carry out their decisions and maintain social values by the use of art forms imbued with meaning".

The "imbued" with "meanings" are the focus of this paper which we term as "symbolic motifs" and their "essence". This is because Ogbu (2005) noted that "the configuration of Igbo modern thrones, their qualities and associated symbolic motifs and accumulation around them occur with frequency in Igbo areas of Anambra State which forms our study area.

The design of this paper will therefore begin with the classification of symbolic motifs on the Igbo modern thrones of Onitsha, Engugu - Ukwu, Nri and Awka. This will be followed by the interpretation of the symbolic motifs. The analysis of the iconography and functions of symbols in the peoples context will be addressed using oral interview, photographs of the thrones and their symbolic motifs.

This paper would unveil the Igbo ideology in the presence of modernization in their use and choice of symbolism. It would also show if there has been shifts or elaborations of symbolism as a result of change in ideology, occupation and general world view. One would want to know whether there has been incorporation of new found motifs, functions and meanings in the presence of change. We would also go further to show the youths restrain and acceptance of tradition and change as a result of urbanization and technology.

\section{Symbolic motifs and modern Igbo thrones}

Apart from the visually intimidating size and structure of many modern thrones. Their symbolic power in projecting leadership authority can be seen from the variety of symbols used for their embellishment (Ozua Oloye). These are carved symbols of swords, Ozo titled figures in their official regalia. (Fig. 1, 2 \& plat 1).

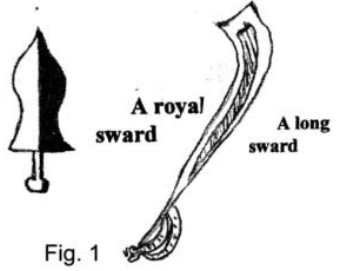

Fig. 1

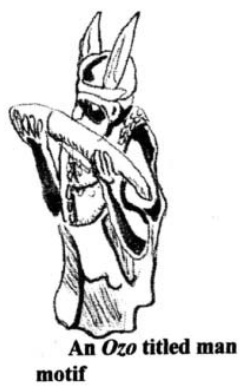

Fig. 2

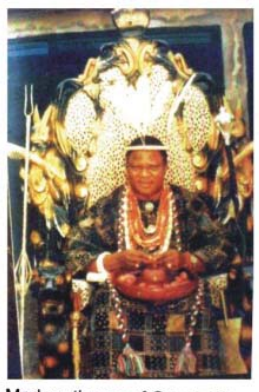

Modern throne of Ozuah Oloye Plate 1

The visual opulence of the thrones is matched by that of the royal dignity of the monarchs themselves who are the (Igwe) decked out in their equally opulent regalia, empowered by their various insignia of office. There are levels of apparent stylistic similarity in some of the thrones. The reason lies in the fact that they were produced by a new crop of carvers who reside in the cities.

They carve these with a combination of traditional tools and modern pneumatic tools which enable them carve very complex and intricate thrones which they sell in shops to patrons who are ready and willing to buy on the spot. Their artistic productions have benefited from modern equipment and technology. Their royal owners while appreciating the visual grandeur of modern thrones proceed to further embellish them with royal regalia, accessories and house furnishing as if the thrones had provided the basic for new forms of installation art (Ogbu 2005).

These Igbo modern thrones are rich in symbolism and can be classified into (a) human symbols (b) animal symbols (c) emblems (d) geometric and floral designs. 
a) Human Symbol: is a symbolic imitation of an Igbo titled man in his rich regalia of a flowing gown, which covers the entire feet, in its richness and opulence. The figure, carved in wood, has traces of realism in the handling of the elephant tusk, crown and even the figures, which grasp tightly the elephant tusk. Power emblems enhancing his leadership authority include elephant tusk, two title feathers, coral beads and the rich regalia. There is a double symbolism in the context. The first is that this power symbols enhance the status of the carved titled figure most probably an Ozo title holder. The figure with its enhancing power symbols in turn reinforce and projects those of the throne as well as the owner who is also a titled leader.

b) Animals and Birds include lions leg, lion's claws, feathers, chameleon, python with an egg in the mouth, a stylized monkey, cow head, monkey head and an elephant, lion with an open mouth (Fig. 3-11).

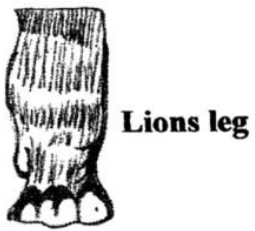

Fig. 3

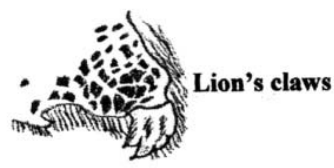

Fig. 4

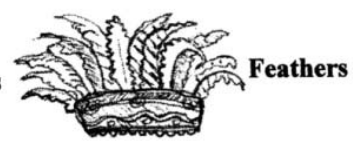

Fig. 5

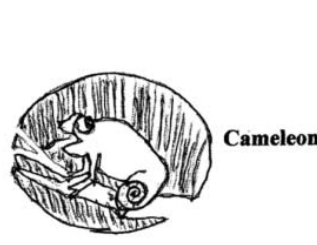

Fig. 6

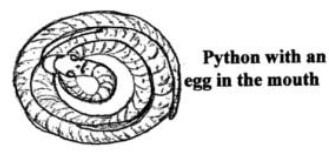

Fig. 7

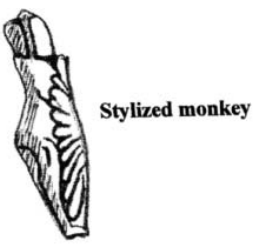

Fig. 8

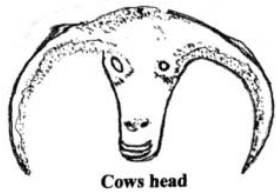

Fig. 9

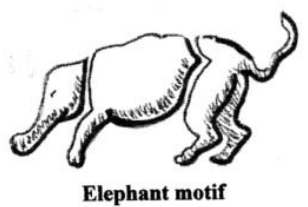

Fig. 10

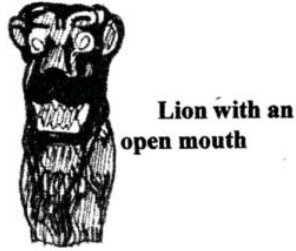

Fig. 11

It is obvious from this category that there are multiple and cross cutting symbols which are underlain by deeper symbolisms.

Their heroic symbolism reference to the title holder and leaders. They are underscored by such symbols as (Fig. $12,11, \& 4)$

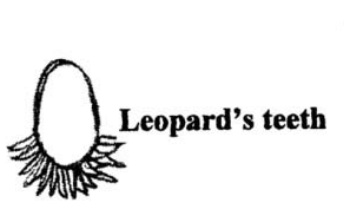

Fig. 12

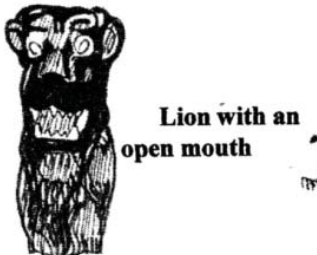

Fig. 11

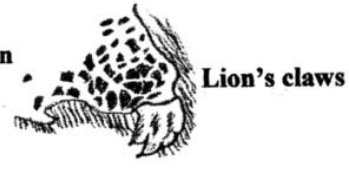

Fig. 4 
The leopard teeth, lion and lion claws. They extend the powerful and heroic status of modern Igbo titled leaders who now purchase or are given thrones which match the materials and social influence of leaders.

In fact, the presence of (Fig. 13)

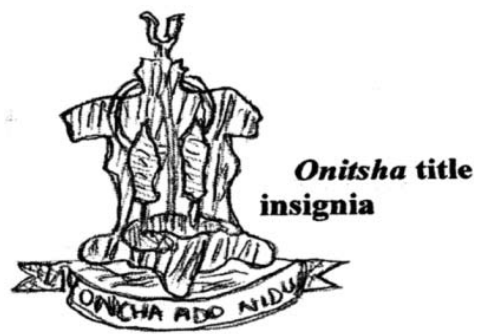

Fig. 13

leopard skins on the headrest of the Obi of Onitsha was reported in 1849 by the Brudo who paid a visit to the Obi Akazua. It is also known that the Obi of Onitsha is a war leader and often greeted with the honorific title of "He who kills one the day life is sweetest (Ozo Ofile Akunia 2005)". Of course, other symbols such as the elephant is a means of underscoring a leaders greatness based on the aesthetics of size. Just as the elephant is the biggest animal in the forest, so is the leader at the apex of the societal hierarchy. Achebe (1964) documented that the python symbol in Igbo cosmology is the daughter of the river goodness (Idemili). He added that "it is that pillar of water that links the earth and the firmament". Any wonder that many modern Igbo leaders bear the honorific title of "Igwe" meaning "the sky deity".

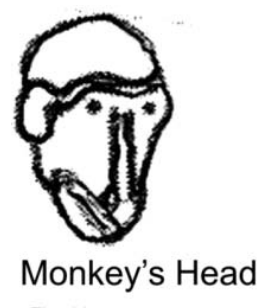

Fig. 14

(Fig. 14) The monkey symbol, according to "Igwe Ogbummuo" the viii of Nri, is a symbol of agility and in extension that of the leader.

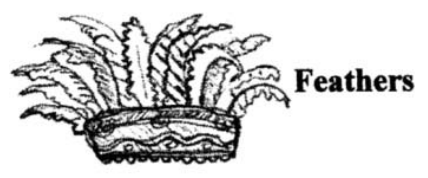

Fig. 5

(Fig. 5) Eagle feather invest their rich symbolism on the leaders as the people's leader eagle which Cole and Aniakor noted as the epitome of innocence and purity.

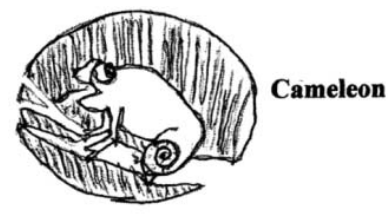

Fig. 6 
(Fig. 6) the chameleon, on the other hand, is according to "Ozo Ofili Akunnia", is cautious, a virtue that is expected of a leader.

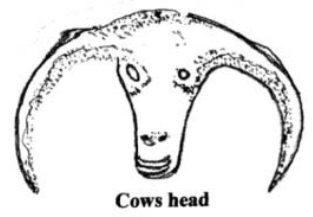

Fig. 9

(Fig. 9) the cow head is read as a symbol of prestige. In the past a leader is known from the number of cow skulls displayed against the alter in a man's reception hall (Ozo Ofili Akunnia 2005).

c) Emblems are:

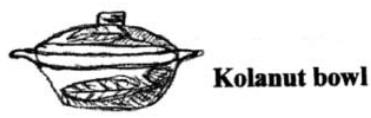

Fig. 15

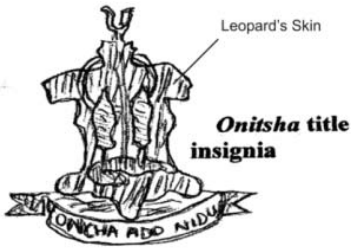

Fig. 13

Kolanut bowl, (Fig. 15). Onitsha title insignia, (Fig. 13)

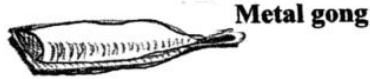

Fig. 16

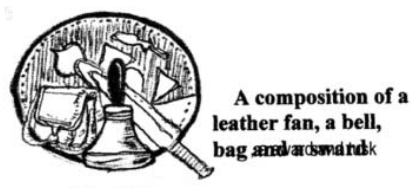

Fig. 17

Metal gong, (Fig. 16). A composition of a leather fan, a bell, bag and a sword) (Fig. 17)

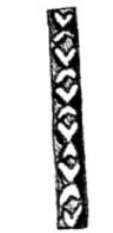

Ofor Staff

Fig. 18

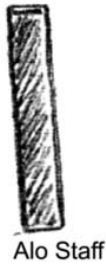

Fig. 19

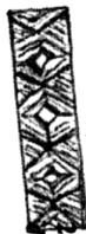

Staff

Fig. 20

"Ofo", (Fig. 18). Alo and (Fig. 19). Otonsi staffs, (Fig. 20) 

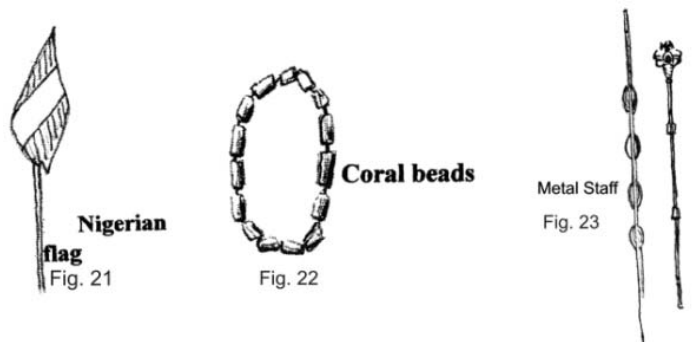

The Nigerian flag, (Fig. 21). A line of coral beads, (Fig. 22). Metal staff of office, (Fig. 23)

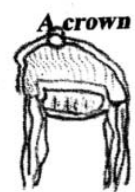

Metal Staff

Fig. 24

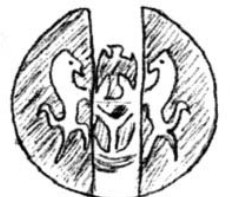

Nigerian Coat of Arms

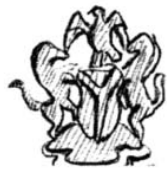

Fig. 25

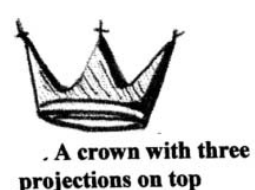

projections on top

A crowns, (Fig. 24). The Nigeria coat of arms, a crown with three projections on the top, (Fig. 25)

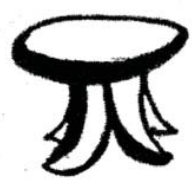

An Ozo title stool

Fig. 26

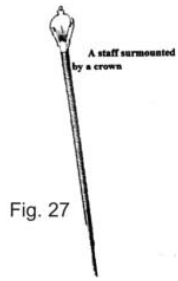

An Ozo title stool, (Fig. 26). A staff surmounted by a crown, (Fig. 27)

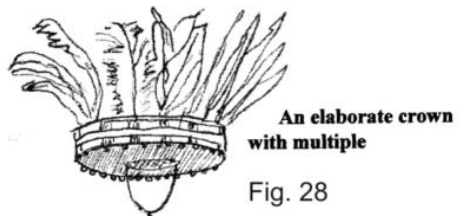

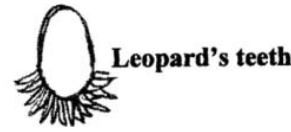

Fig. 12

An elaborate crown with multiple feathers, (Fig. 28), and leopard teeth and (Fig. 12)

The three groups of symbols serve as important activators of leadership, power and authority. This is why they have been in their diverse and sometimes profuse number to beautify and project leadership power in the context of modern Igbo leadership institution. Their diversity is a pointer to their difference sources of borrowing in an urban melting point and in accordance with Ottenbeng (1959) and Bravmann (1973).

More details are further revealing. For example, many of the modern thrones bear the images of the Nigeria coat of arms and flags perhaps as a way of projecting the legitimacy of leadership authority in a modern context. Various types of leadership staffs underscore the status of economic symbolism as well as individual prestige. Crowns whose sources may have been almanacs and calendar are mandatory items for modern lgbo leaders and thus carry some source of political symbolism, which is also aesthetic.

d) What is known about geometric and floral (Fig. 30) 

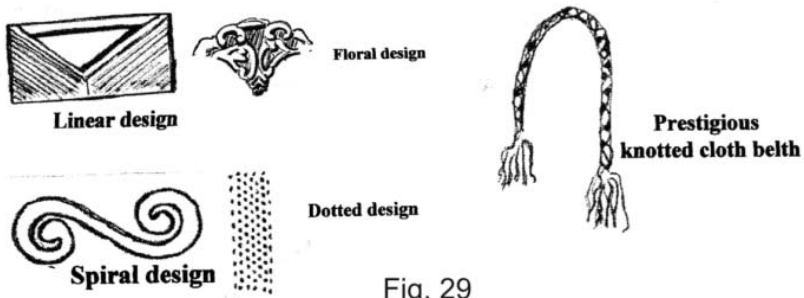

Fig. 29

In Igbo designs is that they are sometimes painted on the walls and the skins and used as incised decorations on carved doors and panels (Cole and Aniakor 1984) Achebe (1964), Uche Okeke (1978) and Aniakar (1978) and Fosu (1986). They are also used as decorative items on Igbo stools (Ogbu 2005). Where such decorative designs are used as forehead markings, they are prestige leader and underscore high status (Onunejeogwu 1981 and Cole and Aniakor 1984). The same is true that they are used as decorative incisions on art objects (Cole and Aniokor 1984 and Aniakor 1972).

Floral and Spiral designs used in the context of modern Igbo thrones are simply for decoration purposes. However, Igwe of Awka explained them as enhancing the leaders' title person. This is why they were selected for decorative use in preferences to other design elements. Their location on modern Igbo thrones carry this type of hidden symbolism (EzeUzu of Awka 2004).

\section{The iconographic and functional analysis of the symbolic motifs}

This section takes up the iconographic and functional analysis of the symbolic motifs which constitute the motifs symbolism on the Igbo modern throne. The individual symbolic motifs discussed under their classified groups above exhibit interplay of interaction and interrelation of symbolic motifs. In this, several traditional and modern functions overlap one another. Our field record reveals that these symbols represent the life and taught of a people whose leaders control and direct the affairs of the community using the power of art symbolism as visual and psychological support in a period of change.

These symbolisms noted the researcher, consist the naturalistic and abstracted representations of a range of motif components of symbolic objects as listed above. That these motifs occur simultaneously on the modern Igbo thrones and in different combinations is noteworthy. We shall trace our field data and highlight on their symbolic functions and meanings.

We shall proceed by citing "Ozo Nnanyelugu" who highlighted that "thrones enjoy monopoly over the valuable materials used in their production. Such materials include beads, imported fabric, elephant etc". "Ozo Ofili Akunnia" on the other hand "detailed that decorative motifs around the modern Igbo thrones are imbued with symbolic notions". These motifs and the throne work together for the preservation of the culture. Although some of the motifs he continued are for aesthetics.

The posture of the Obi of Onitsha seated on the throne for instance, (Fig. 31) 


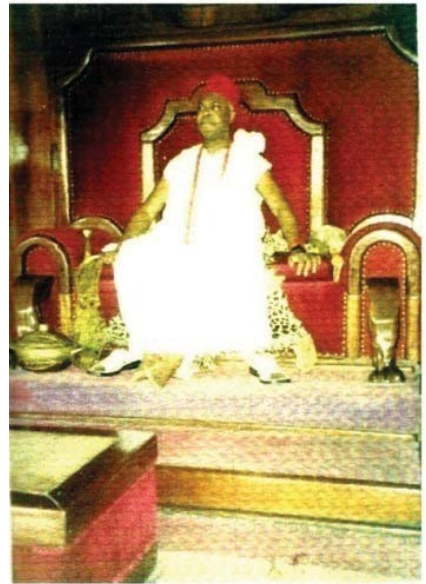

Plate 2

Evokes some praise names, some of which he stated as attribute of some powerful animals.

They are a lion (agu), when a lion enters the bush, other animals run away (agu bata ofia, umu anunu agbafuue), the lion's hand is more active than the work done by it (aka agu ka olu ya ).

He went further to say that "ufie" is a musical instrument. It serves as a time keeper in waking up the "Igwe' because he breaks kolanut and prays every morning. Skins of powerful animals are games killed by the villagers and brought to him as tribute. The python is a superior animal; the egg in its mouth represents the delicate affairs of the community in the hands of the ruler. The chameleon is a symbol of power and a powerful metaphor for political governance. Its characteristic attribute means that the ruler should be diplomatic in approaching issues is in keeping with the changing nature of the creature (Akunia Ofile 2004).

These characteristic attributes are visually displayed on the throne to evoke its metaphoric presence. It also makes audibly apparent its functions and meanings (oral communication by Ozo Ofili Akunnia 2005).

Contributing in that order is "Ozo Osita Oranye" who quipped that the "staff of office "abana" is a sacred symbol just as the throne. He further explained that an elephant legs on the throne revealed that throne is equally the largest seat in the community as such its owner is expected to have the largest number of visitors. This entails the breaking of kolanut at will.

The coral bead is a symbol of status depicting the Obi as a titled leader. With pride, Ozo Ofili explained that the crest above the throne is a reminder to the ruler and the community of their ancestral home at Ado n'idu in Benin, Edo State of Nigeria. Practices which suggest movement of art objects across their frontier Bravmann (1973).

These levels of manifest symbolisms are embodiments as well as encapsulations of tradition and culture of the people and emits aura of royalty and political authority.

On his part, the "Adama Nri" narrates that thrones attract accumulations of motifs around it. These motifs he says "add in creating vibrant environment through their associated functionality to the thrones", one of which is "reinforcement to royal authority as well as the distinquishment of its owner from the ordinary person.

The "Igwe" of "Nri", "Igwe Ogabumnuo" the viii has a symbolic lion with an open mouth and a flying monkey engraved on his throne.

For this he explained that "I am a lion, and before I speak, I have to reason out my thoughts because whatever I say becomes a law". The monkey symbolizes me as an agile and alert ruler. The coat of arm on my throne shows the federal government involvement in our village communal life and political activities". The throne itself is a composition of symbolic assemblage and a storage of a system of symbolic information pertaining to kingship, royalty and the community. This is because the "Igwe" himself acknowledged that "what people fear is what they see" (ife natu mmadu egwu bu ife onye ahu n'afu nanya).

All forms of symbolic motifs around the modern Igbo throne underscore historical facts. Some reflects the modern trend in Igbo life, while others maintain the strength of tradition. But when put together, they form part of the throne because according to Ozo Ikebulem "birds feather constitute the dignity of the bird". (abuba okuku so n'ugwu okuku). 
Christian motifs on the throne he retraced "revealed the impact of Christianity on Nri Igbo culture. Symbolic motifs on the thrones help to project it as a historical document through which we know our root and the journey so far".

"Igwe Ogbummuo" further added that "some motifs reflects the modern concept of power with it political shifts and values". This is why he observed that "people do not get to the river before they cross it ("ufodu mnadu adaa eru nammiri were kufe). Throne on its own is a symbolic art object because it provides visual indices of power through its motif components. From these we learn that some plants and animals are more powerful, more valuable and more important in the society than others.

These motif components underscore the historical facts, the wealth and the position of a powerful leader. For example, the "ofo", "alo" and "Otonsi" are staffs of truth and justices, ritual staff and the staff for the cleansing of abomination in that order in Igbo land. These staffs retrace the validity of deeper spiritual values that underline stable moral leadership as well as providing indices of power and authority in governance. "This is because everything about the motifs are of great value, power and morality. They are on the whole the encapsulations of the complex meaning of our culture and tradition which when decoded fully embrace all about us" (Ozo Igwe bu obu 2005).

The practical and symbolic value of these motif components are dramatized in the formal structure of the Igbo modern thrones particularly when it appears in the contest of a particular cultural event. For example, in ceremonial activities, thrones are elevated beyond artistic utility to become emblem of history, authority and power. (Ogbu, 2005). This is because the compressed and varied ideological statement made by the motif components on the throne give it a greater power than are lodged in a mere sitting material which is as a result of the superior status expressed in its visual aggrandizement: the open work designs, powerful animals and various intricate designs, lofty height, wide expanse of space and accumulations plus other phenomenal objects around it that made the Igbo modern throne a status symbol and gave it the strength to invoke power, authority, unquestionable royal command, mystique, resonate as well as humbling spectacle. 
GRAPHIC ILLUSTRATIONS/PHOTOGRAPHS OF IGBO MODERN THRONES AND THEIR SYMBOLS
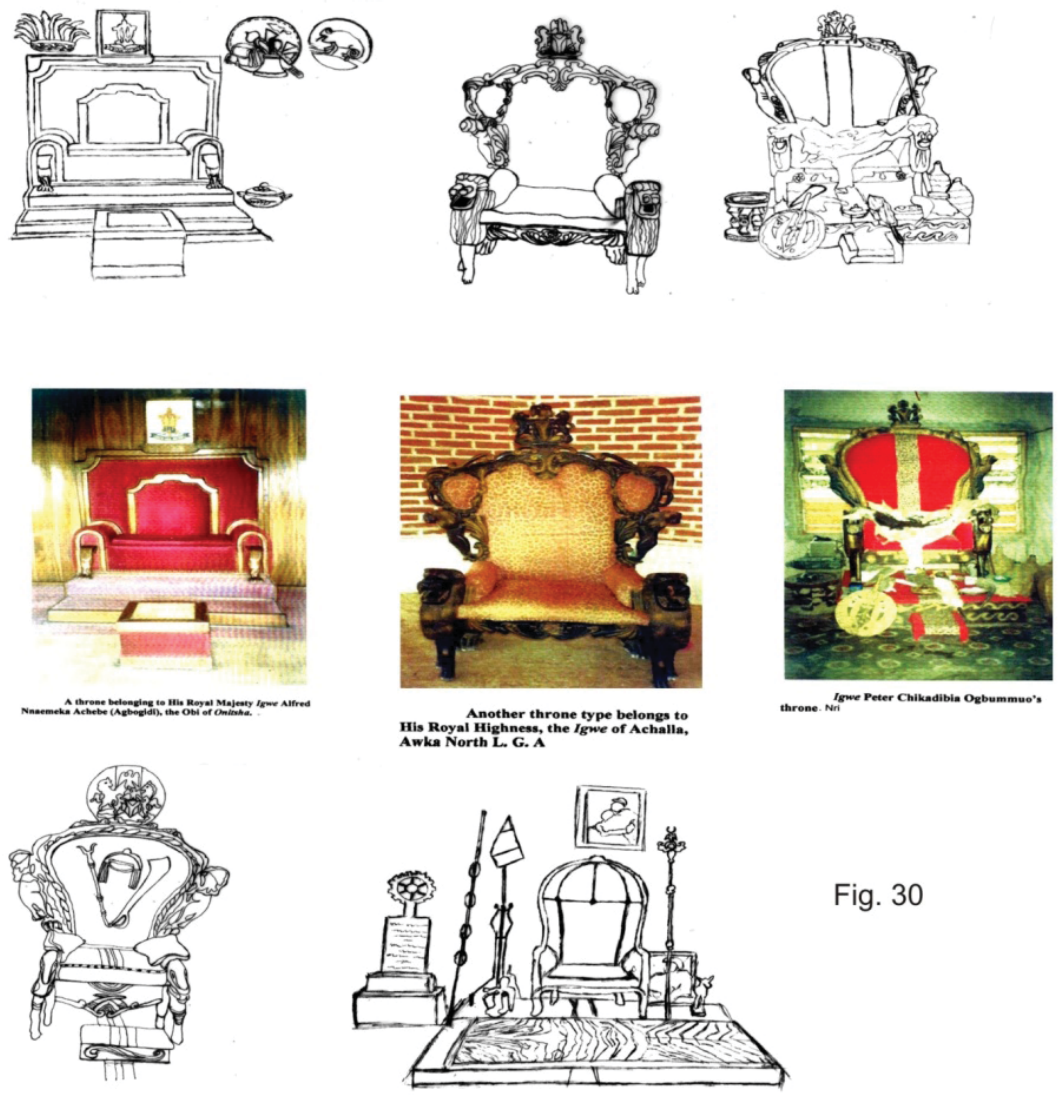

Fig. 30
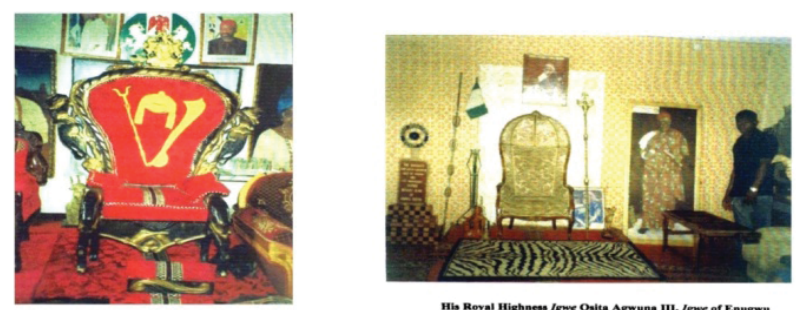

Ene Uno In, the
modern throne

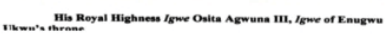

\section{Conclusion}

It is only logical to reach a number of conclusions from the proceeding passages on this study. First is that the energetic and dynamic Igbo are richly endowed with material culture which are incorporated into their artifacts and serve as the encapsulation of the peoples ideology of cosmology.

In terms of creativity, the Igbo are at the forefront of the crusades as epitomized in their skillful and expertise control of art media and material as expressed in Awka smith and their igbo-ukwu counterpart. Thrones on their part, show it as the embodiments of unrestrained authority and signal their commanding political status and influence. Its symbols embellish it with surface richness. In terms of function and iconography, they conceptualize the primordial link 
between leaders and the ancestors that provides the ritual sanctions for the maintenance of law and order. They also enhance ritually the quality of interior space of royalty. They at the same time retrace the validly of deeper spiritual values that underline stable moral leadership. These are seen in the ornate presence of such symbols as ofo, otonsi and alo.

More importantly, is the fact that Igbo modern thrones define mystical status of leaders. In their overt and hidden symbolism, they manifest material and social influence. In their study presence also, they reinforce the ideals of modern Igbo leadership.

Furthermore, the various symbols of the animals, plants, emblems and frofal/geometric motifs reference to the dynamic nature of the Igbo world in a period of change. This is because, the general feature of the thrones and their symbols show them the ultimate indicator of Igbo notion and ideal of power in modern context. Hence, tradition and change are reflected visually in functions and iconography of symbolisms in leadership contexts.

The finding of the research is as follows: (1) These symbols represent the life and taught of a people whose leaders control and direct the affairs of community using the power of symbols as visual and psychological support. (2) The decorative motifs are imbued with symbolic notions for the preservation of culture as well as aesthetics. (3) The levels of manifest symbolisms are embodiment as well as encapsulation of tradition and culture of a people and emit aura of royalty and political authority. (4) They also create vibrant environment through their associated functionality and iconography, one of which is the reinforcement of royalty and distinguishing him from the ordinary people. (5) All forms of symbolic motifs underscore historical facts in that while some reflect the modern trend in lgbo life such as the coat of arms, flags, almanac etc others maintain the strength of tradition. (6) Christian motifs on their part, retrace the impact of Christianity in Igbo culture. (7) above all, the symbols remain a historical document of a peoples past, present and a light to direct their future. At the same time some reflect the Modern concept of power with its political shift and values. (8) Symbols also provide visual radices of power through their motifs components in their revelation of the worth, qualities and essence of the animals and plants which they depict as more powerful, valuable, and important in the society than others. (9) On the whole, they constitute the combination of a complex meaning of a peoples culture and tradition which they bear upon and when decoded are all embracing and revealing.

At this end, it is observed that the practical and symbolic values of the motifs dramatize the formal structure of the Igbo modern thrones, especially when they appear in context of an event. This is because, they elevate art objects beyond artistic utility to become an emblem of history, power and authority. The reason lies in the composition and various ideological statements which gave the art object a greater power than are lodged in a mere sitting material as a result of superior status composed in their visual aggrandizement:- animals, plants, emblems and cosmic motif which gave it the power to evoke strength, royal command, mystique and resonate.

Finally, our field experience revealed that modern implements quickened the production of complex and intricate designs which led to mass production of Igbo modern thrones which are seen displayed in shops in the cities ready for sale to those who are ready to buy on the spot for added regalia. Ironically, we noted that some of the Igwes could not explain, identify or fully interpret some traditional art symbols rather the new ones which they incorporate into their homes and offices. This is because of inconsistencies in the political institutions which is a child of modernization and change: an attribute of long stay oversees, urban towns, involvement in government works, politics and western education. Other reasons behind this include a drop in participation in communal village affairs, and lack of close contact with the custodian of oral history, culture and tradition which are acquired gradually and at a long period of time.

Youth restiveness on its part contributed in no small measures to this ugly trend. They show no interest in the village activities with its attendant values, wisdom and ideals of life which comes with age and apprenticeship. As a result, they could barely answer questions on culture and tradition such as proverbs, folk tell, songs dances, idioms etc. worst are the distractions by modernization, urbanization and technology with their computer driven activities. Unless a drastic intervention is made to cub this negative attitude towards their cosmology, our cherished culture and tradition will fast extinct. Regrettable is the erosion of our cherished dressing code, manner and lack of knowledge in the presentation and breaking of kola-nut which is the Igbo in an Igbo man.

We posit that positive action should be taken very fast to check this ugly trend before "things fall apart and the center can not hold so that the heresy will not be loosen on our dear land" and put us on a pendulum belonging to neither here or there because an Igbo adage goes that "onye hepu irache onu ya, uguru aracha ya" if one does not lick his mouth, the harmattarn does it for him.

\section{References}

Achebe, C. (1964): Arrow of God, London, Heinemann. 
Aniakor, C.C (1978) Igbo Architecture: A Study of Forms Functions and Typology I \& II PhD Dissertation, University of Indiana Bloomington.

Bravmann, R. (1973) Open Frontiers: The Mobility of Art in Black Africa, Seattle, University of Washington Press.

Brudo, A. (1980) The Niger and the Benue. London.

Cole H and Aniakor C. (1984) Igbo Art, Community and Cosmos. Los Angeles, University of California, Museum of Natural History.

Cole, H.M (1972) Igbo Art and Authority". In D. Fraser and H. M. Cole (eds) African Arts and Leadership. Madison. University of Wisconsin Press.

Eyo, E. (1977). Two Thousand Years Nigeria Art. Federal Department of Antiquities Lagos.

Fag, W. and Plass, M. (1964) African Sculpture, London. Dutton.

Fosu, K. (1986) 20th Century Art of Africa. Gaskiya, Corporation Limited Zaria. Nigeria.

Nsofor, M.C (1977) "Igbo-Ukwu Bronzes", History made by a Farmer. Ugo Magazine. Ministry of Education and Information vol. 1 No. 1 Enugu.

Oftenberg, S. (1959) "Igbo receptivity to change. In B. William and H. Melville (eds), community and change, Chicago, Chicago and London. The University of Chicago Press 130-143.

Ogbalu, F.C (n.d) Igbo Institutions and Customs, Onitsha University Publishing Company Limited.

Ogbu, C. H (2005) Igbo Stools and Thrones as Icons and ideals of power. Unpublished PhD Thesis University of Nigeria Nsukka.

Okeke, U. (1982) Art in Development: A Nigerian Perspective Documentation Centre, Asele, Nimo.

Onwuejeogwu M. A (1972) "An outline of the down Igbo Civilization". In Odinani: Maiden Issue. The Journal of Odinani Museum Nri. (1) Onwuejeogwu, M. A. (1981) An Igbo civilization, Nri Kingdom and Hegimony, London; Ethnographica.

Oyelola, P. (1976). "Everymans Guide to Nigerian Arts", 1st Published by Nigerian Magazine. Cultural division. Federal Ministry of Information, Lagos.

Shaw T. (1970) Igbo - Ukwu: An Account archeological discoveries in eastern Nigeria: London Faber and Faber Limited.

Shaw, T (1977) Unearthing Igbo-Ukwu: Archaeological discoveries in eastern Nigeria. London Oxford University press. 